\title{
Diabetic ketosis in children treated by adding low-dose insulin to rehydrating fluid
}

\author{
P. N. MALLESON \\ From Derbyshire Children's Hospital, Derby
}

\begin{abstract}
Malleson, P. N. (1976). Archives of Disease in Childhood, 51, 373. Diabetic ketosis in children treated by adding low-dose insulin to rehydrating fluid. Four children with severe diabetic ketosis were successfully treated with a regimen of low-dose intermittent insulin infusions in the rehydrating fluid. The children all rapidly regained consciousness and tolerated oral fluids within 12 hours of admission. Hypoglycaemia and hypokalaemia, both complications of conventional large dose insulin treatment, did not occur. Plasma insulin levels obtained by this method were maintained in the optimum range recommended by Sönksen et al. (1972).
\end{abstract}

Recently the use of continuous low dose infusions of intravenous insulin in the treatment of diabetic ketosis in adults has been reported (Sönksen et al., 1972; Page et al., 1974; Kidson et al., 1974; Semple, White, and Manderson, 1974). The methods described have necessitated the use of an insulin and physiological saline mixture, often with added human albumin, delivered through a separate paediatric giving set or syringe pump from that delivering the rehydrating solution. There have been no reports specifically of its use in children, though 6 of the cases described by Page et al. (1974) were under 14 years of age. We have successfully treated 4 children in diabetic 'coma' with small doses of insulin mixed with the rehydrating saline, so simplifying the clinical management, and describe them in this report.

\section{Patients}

Case 1. A 12-year-old known diabetic girl, who had had four previous admissions with diabetic ketosis.

Received 27 August 1975.
She was receiving 70 units of lente insulin daily but was poorly controlled owing to reluctance to keep to her diet. She had been well until 24 hours before admission, though urine tests had consistently shown $2 \%$ sugars for several days. She then began to complain of abdominal pain with increasing thirst and polyuria, and was admitted to hospital, having already had her usual daily insulin. She was pale, semicomatose with acidotic respirations, and had poor peripheral circulation. Weight was $45 \mathrm{~kg}$.

Initial investigations which confirmed the diagnosis of severe diabetic ketosis are shown in Table I. She was treated with intravenous physiological saline at $100 \mathrm{ml} /$ hour, and after an intravenous bolus of 5 units of soluble insulin she received 4 units of soluble insulin every hour as described below. After 8 hours plasma glucose was $<300 \mathrm{mg} / 100 \mathrm{ml}$ and she was tolerating oral fluids, so insulin was given subcutaneously according to urine sugar concentrations. Intravenous fluids were stopped after 12 hours.

Case 2. A 12-year-old boy was admitted with a 3-week history of polyuria and polydipsia. On examination he weighed $33 \mathrm{~kg}$, was dehydrated and acidotic, and was semicomatose; his tonsils were infected.

\section{TABLE I}

Biochemical data from 4 children with diabetic ketosis before starting treatment

\begin{tabular}{|c|c|c|c|c|}
\hline Initial plasma levels & Case 1 & Case 2 & Case 3 & Case 4 \\
\hline $\begin{array}{l}\text { Glucose }(\mathrm{mg} / 100 \mathrm{ml}) \\
\text { Bicarbonate }(\mathrm{mEq} / \mathrm{l}) \\
\text { Urea }(\mathrm{mg} / 100 \mathrm{ml}) \\
\text { Potassium (mEq/l) } \\
\text { Urine ketones (Acetest) }\end{array}$ & $\begin{array}{c}492 \\
3 \\
42 \\
5 \cdot 5 \\
+++\end{array}$ & $\begin{array}{c}560 \\
6 \\
51 \\
5 \cdot 0 \\
+++\end{array}$ & $\begin{array}{c}1040 \\
4 \\
122 \\
4 \cdot 3 \\
+++\end{array}$ & $\begin{array}{c}458 \\
5 \\
85 \\
4 \cdot 0 \\
+++\end{array}$ \\
\hline
\end{tabular}


Diagnosis of diabetic ketosis was confirmed by the results of initial investigations shown in Table $\mathrm{I}$. $\mathrm{He}$ was given intravenous physiological saline at $150 \mathrm{ml} /$ hour, and after an initial dose of 10 units of soluble insulin was treated with 4 units of soluble insulin per hour intravenously as in Case 1. After 3 hours plasma glucose was $<300 \mathrm{mg} / 100 \mathrm{ml}$ and he was taking oral fluids. He was then changed to subcutaneous insulin and intravenous fluids were stopped after 17 hours.

Case 3. A 7-year-old girl had been completely well until one month before admission when she developed increasing polyuria, polydipsia, and lethargy. She weighed $33 \mathrm{~kg}$, was severely dehydrated, drowsy, had acidotic respirations, and a poor peripheral circulation. Initial investigations confirmed the diagnosis of diabetic ketosis (Table I). She was treated with intravenous physiological saline at $150 \mathrm{ml} /$ hour and given an initial dose of 15 units of soluble insulin intravenously followed by 5 units of soluble insulin hourly by infusion. After 14 hours plasma glucose was $<300 \mathrm{mg} / 100 \mathrm{ml}$, she was fully conscious, and was tolerating oral fluids. She was then changed to subcutaneous insulin according to urine testing and intravenous fluids were discontinued after 32 hours.

Case 4. A 14-year-old known diabetic boy, who had had one previous admission with severe diabetic ketosis complicated by persistent hypokalaemia, was admitted after 8 hours of acute diarrhoea and vomiting. He weighed $40 \mathrm{~kg}$ and though moderately alert was dehydrated and had acidotic breathing. Investigations confirmed diabetic ketosis (see Table I). Unlike the previous cases he was initially treated with intravenous saline only, receiving $800 \mathrm{ml}$ in the first 3 hours. He was then given physiological saline at $150 \mathrm{ml} /$ hour intravenously with 4 units of soluble insulin added every hour.

After 8 hours of intravenous insulin plasma glucose was $<200 \mathrm{mg} / 100 \mathrm{ml}$, he was no longer acidotic, was drinking well without nausea, and was therefore given insulin according to urine sugar concentrations. Intravenous fluids were discontinued after 24 hours. Just before starting insulin therapy and at intervals during the first hour after insulin was added to the rehydrating fluid, blood was taken from the arm opposite to that receiving the infusion in order to measure the peak and duration of plasma insulin rise obtained by this method. The resulting curve is shown in Fig. 2.

\section{Methods}

Insulin dosage in all cases was approximately 0.1 unit/kg body weight per hour. The exact dosages are shown in Table II. Case 1 received 0.09 unit $/ \mathrm{kg}$ per hour; Case 2, 0.13 unit $/ \mathrm{kg}$; Case 3 received 0.17 unit $/ \mathrm{kg}$; Case 4 received $0 \cdot 10$ unit $/ \mathrm{kg}$.

Insulin was given in the rehydrating solution by adding the hourly amount to a full $30 \mathrm{ml}$ drip chamber. In this way the insulin was delivered intermittently over a period of approximately 10-15 minutes every hour depending on the rate of flow of the rehydrating infusion. No human albumin was added. Sodium bicarbonate was added initially in a quantity calculated to correct half the base deficit. Potassium chloride was added to the infusion bottle as soon as each child had passed urine.

\section{Results}

The 4 children all recovered rapidly. Plasma glucose levels fell steadily as shown in Fig. 1.

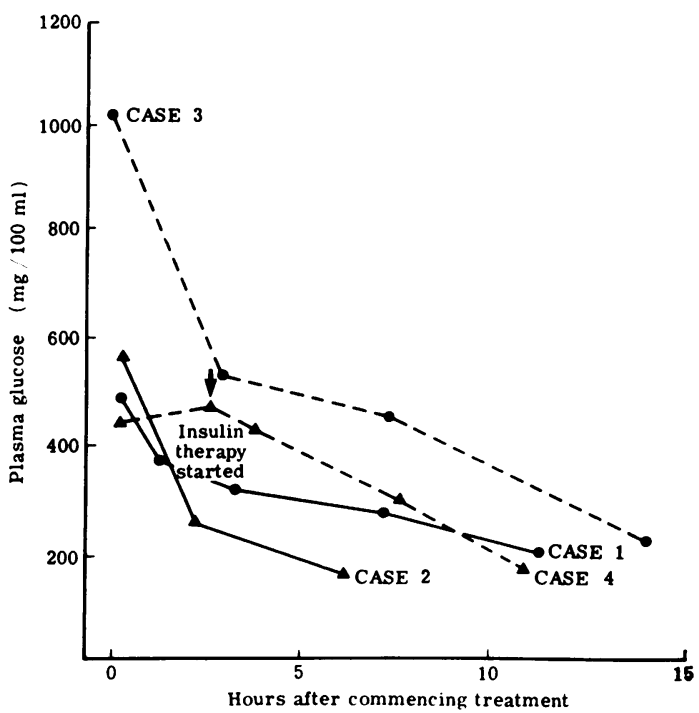

Fig. 1.-Fall in plasma glucose in 4 children with diabetic ketosis treated with low-dose intravenous insulin given intermittently into the rehydrating drip chamber. Case 4 only received insulin from 3 hours.

TABLE II

Dosage values in therapy of 4 children with diabetic ketosis

\begin{tabular}{|c|c|c|c|c|}
\hline & Case 1 & Case 2 & Case 3 & Case 4 \\
\hline $\begin{array}{l}\text { Initial dose insulin (units) } \\
\text { Maintenance dose } \\
\text { (units/kg per hour) } \\
\text { Total dose insulin intravenously } \\
\text { (units) } \\
\text { Total volume intravenous fluid (ml) } \\
\text { Total dose intravenous potassium (mEq) }\end{array}$ & $\begin{array}{l}5 \\
0 \cdot 09 \\
41 \\
2000 \\
20\end{array}$ & $\begin{array}{l}10 \\
0 \cdot 13 \\
26 \\
2900 \\
100\end{array}$ & $\begin{array}{l}15 \\
0 \cdot 17 \\
50 \\
3600 \\
80\end{array}$ & $\begin{array}{c}4 \\
0 \cdot 10 \\
32 \\
3500 \\
90\end{array}$ \\
\hline
\end{tabular}


The mean rates of fall of plasma glucose were Case $1,47 \mathrm{mg} / 100 \mathrm{ml}$ per hour; Case $2,100 \mathrm{mg} / 100 \mathrm{ml}$ per hour; Case 3, $59 \mathrm{mg} / 100 \mathrm{ml}$ per hour; Case 4, $36 \mathrm{mg} / 100 \mathrm{ml}$ per hour (from the time of adding the insulin). The total dose of intravenous insulin used in each case was small: Case 1, 41 units; Case 2, 25 units; Case 3, 50 units; Case 4, 32 units. They received in total $2000 \mathrm{ml}, 2900 \mathrm{ml}, 3600$, and $3500 \mathrm{ml}$ of saline, and $20 \mathrm{mEq}, 100 \mathrm{mEq}, 80 \mathrm{mEq}$, and $90 \mathrm{mEq}$ of potassium, respectively (see Table II).

Plasma insulin levels in Case 4 during the first hour after administration of 4 units of insulin show a rise from a level of $42 \mu \mathrm{U} / \mathrm{ml}$ before therapy to a peak of $188 \mu \mathrm{U} / \mathrm{ml}$ at 25 minutes, followed by a fall of approximately $4 \mu \mathrm{U} / \mathrm{ml}$ every minute to a level of $68 \mu \mathrm{U} / \mathrm{ml} 55$ minutes after insulin was added to the drip chamber (Fig. 2).

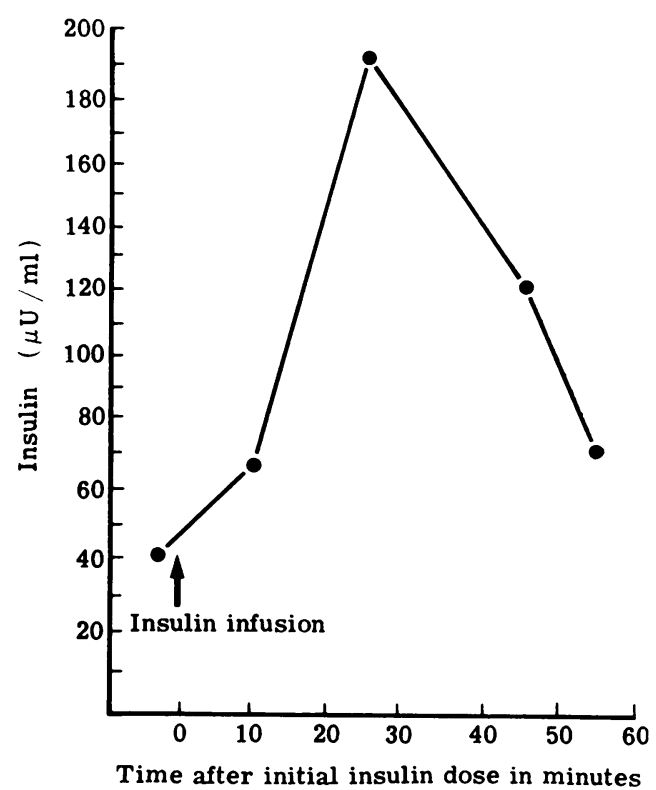

Fig. 2.-Plasma levels obtained in Case 4 during the first hour of infusion of 4 units of insulin.

\section{Discussion}

With the use of small doses of soluble insulin delivered intermittently in the rehydrating solution, we successfully treated 4 children in severe diabetic ketosis. They rapidly regained consciousness and began tolerating oral fluids. Plasma glucose levels fell at a mean rate of $60 \mathrm{mg} / 100 \mathrm{ml}$ per hour. In adults, Alberti, Hockaday, and Turner (1973) suggested the use of small doses of intramuscular insulin repeated regularly in the treatment of diabetic ketosis, thus maintaining plasma insulin levels in the range of $20-200 \mu \mathrm{U} / \mathrm{ml}$ as recommended by Sönksen et al. (1972).

Moseley (1975) using initial doses of $0.25 \mathrm{unit} / \mathrm{kg}$ body weight followed by $0 \cdot 1$ unit $/ \mathrm{kg}$ hourly of intramuscular insulin successfully treated 12 children in diabetic ketosis. Baum, Jenkins, and Aynsley-Green (1975) also treated 3 children in diabetic ketosis with low-dose intramuscular insulin. They had previously established that a mean dose of $0.29 \mathrm{unit} / \mathrm{kg}$ of body weight (range $0.07-0.82 \mathrm{unit} /$ $\mathrm{kg}$ ) given to $17 \mathrm{new}$ childhood diabetics who were not clinically dehydrated or in a 'coma' resulted in a mean plasma insulin level of $65 \mu \mathrm{U} / \mathrm{ml}$ (range 25$102 \mu \mathrm{U} / \mathrm{ml}) 2$ hours after injection. They failed to show a correlation between the dose of insulin administered per $\mathrm{kg}$ body weight and the plasma concentration of insulin obtained at 2 hours, presumably due to variations in the rate of absorption of insulin from the intramuscular depots. The use of low-dose continuous intravenous infusions of insulin has been recommended (Sönksen et al., 1972; Page et al., 1974; Kidson et al., 1974; Semple et al., 1974). This method is successful whether or not human albumin is added to the insulin solution to prevent adsorption of the insuli.in to the plastic. However, even without added albumin, the method necessitates a separate paediatric giving set or syringe pump from that delivering the rehydrating fluid and the preparation of an insulin-saline mixture that has to be reconstituted every few hours, thus considerably complicating the management.

Our method is simpler; only the rehydrating infusion is required as the insulin is added direct to the drip chamber. With this method we obtained a mean plasma glucose fall of approximately $50 \%$ in the first 4 hours, which is similar to that obtained by Alberti et al. (1973) and Page et al. (1974). The results from Case 4 indicate that a satisfactory plasma insulin level is obtained between each insulin bolus. The initial level of $42 \mu \mathrm{U} / \mathrm{ml}$ in Case 4 was presumably due to the lente insulin he had received at home before admission. After starting insulin infusion the levels rose rapidly to near the maximum optimum level recommended by Sönksen et al. (1972), and over the hour remained well within the optimum range, still being $50 \%$ above the pretreatment level when the next insulin dose was due to be added to the drip chamber. Although several authors, including Alberti et al. (1973), have commented on the importance of rehydration in obtaining rapid falls in plasma glucose, these levels may not fall until insulin is started, as illustrated in Case 4. 
Intravenous administration of insulin is preferable to intramuscular as it reduces the number of injections the child has to receive and removes the risk of variable insulin absorption from the intramuscular depots. As in other published cases of diabetic ketosis treated with low-dose insulin, our 4 children had no hypoglycaemic or hypokalaemic episodes, both of which are real risks with conventional large dose methods. It is our impression also that these children, though severely ill on admission, regained consciousness earlier and tolerated oral fluids sooner than children treated with conventional large doses of insulin.

I thank Drs. M. Moncrieff and L. Arthur for permission to present cases under their care; also Miss $\mathbf{R}$. Millner for the preparation of this manuscript, and Charing Cross Hospital medical illustrations department.

\section{REFERENCES}

Alberti, K. G. M. M., Hockaday, T. D. R., and Turner, R. C. (1973). Small doses of intramuscular insulin in the treatment of diabetic 'coma'. Lancet, 2, 515.
Baum, J. D., Jenkins, P., and Aynsley-Green, A. (1975). Immediate metabolic response to a low dose of insulin in children presenting with diabetes. Archives of Disease in Childhood, 50, 373.

Kidson, W., Casey, J., Kraegen, E., and Lazarus, L., (1974). Treatment of severe diabetes mellitus by insulin infusion. British Medical Fournal, 2, 691.

Moseley, J. (1975). Diabetic crises in children treated with small doses of intramuscular insulin. British Medical fournal, 1, 59.

Page, M. McB., Alberti, K. G. M. M., Greenwood, R., Gumaa, K. A., Hockaday, T. D. R., Lowy, C., Nabarro, J. D. N., Pyke, D. A., Sönksen, P. H., Watkins, P. J., and West, T. E. T. (1974). Treatment of diabetic coma with continuous low-dose infusion of insulin. British Medical fournal, 2, 687.

Semple, P. F., White, C., and Manderson, W. G. (1974). Continuous intravenous infusion of small doses of insulin in treatment of diabetic ketoacidosis. British Medical fournal, 2, 694.

Sönksen, P. H., Srivastava, M. C., Tompkins, C. V., and Nabarro, J. D. N. (1972). Growth-hormone and cortisol responses to insulin infusion in patients with diabetes mellitus. Lancet, 2, 155.

Correspondence to Dr. P. N. Malleson, Department of Paediatrics, Charing Cross Hospital, Fulham Palace Road, London W6 8RF. 